\title{
Quality of life - an important parameter of cardiac rehabilitation in heart failure patients
}

\author{
Anca Daniela Farcaș ${ }^{1,2}$, Laura Elena Năstasă ${ }^{3}$, Florin Petru Anton ${ }^{1,2}$, Mirela Anca Stoia ${ }^{1,2}$, Cerasela \\ Mihaela Goidescu ${ }^{1,2}$, Mocan Diana Larisa Hognogi ${ }^{1,2}$, Mihaela Mocan ${ }^{1,2}$, Camelia Larisa Vonica ${ }^{2,4}$, \\ Luminița Animarie Vida-Simiti ${ }^{1,2}$
}

Corresponding author: Năstasă Laura Elena, E-mail address: lauranastase@unitbv.ro

Balneo Research Journal DOI: http://dx.doi.org/10.12680/balneo.2018.198

Vol.9, No.3, September 2018

p: $288-290$

\footnotetext{
${ }^{1}$ Internal Medicine Department, “Iuliu Hatieganu” University of Medicine and Pharmacy, Cluj-Napoca

${ }^{2}$ Cardiology Department, Emergency Clinical County Hospital, Cluj Napoca

${ }^{3}$ Faculty of Psychology and Educational Sciences, Transilvania University of Brasov

${ }^{4}$ Medical Specialities Department, “Iuliu Hatieganu” University of Medicine and Pharmacy, Cluj-Napoca
}

\section{Abstract}

Heart failure is a significant healthcare problem, because of its impact at the individual and populational level, through multiple rehospitalizations and increased morbi-mortality. At the individual level, the multidimensional impact of this clinical condition and its treatment on patients' daily lives is reflected in the quality of life (QoL). QoL needs to be accurately measured, because it's related to high hospitalization and mortality rates and provides valuable information that cannot be directly obtained using clinical, biological or imaging measurements. For these reasons, QoL evaluation (global score, subscale scores, answers to various items, etc.) is a significant parameter for assessing the impact of and for structuring the cardiac rehabilitation programs (exercise training, nutritional counseling, psychosocial support and interventions, etc). In order to increase the long-term efficiency, these programs need also to include strategies to optimize and increase adherence to lifestyle changes and to medical therapy.

Key words: heart failure, quality of life, cardiac rehabilitation

\section{Introduction}

Heart failure (HF) - a possible end-stage of every cardiac disease - is found in $1-2 \%$ of adults worldwide and a significant topic in health care. Moreover, despite significant progress in therapy, the increased prevalence of HF is dramatic. Living with HF causes a significant stress that patients have to cope with [1], frequent rehospitalizations - 4-5 /year and on average $25 \%$ in the first year following diagnosis- [2], increased comorbidities and high mortality rate [3]. There are several prognostic factors - some of them modifiable - that influence the outcome of HF[4-8]. However, clinical trials have shown that this disabling condition has a modifiable course and a large potential for improving using cardiac rehabilitation programs. These programs vary but in order for them to be efficient they need to be multidisciplinary and comprehensive, similar to rehabilitation programs for other conditions such as diabetes [9, 10]. Their goals are to recover (and restore) the physical, social and mental well-being, thus improving the outcomes and correcting the risk factors that influene the incidence (and outcome) of cardiovascular diseases [11, 12].

HF has a detrimental effect on daily routine through various physical simptoms, psychological reactions and their treatment, thus lowering the quality of life (QoL) [13]. WHO [14] defines Quality of Life as individuals' perception of their position in life in the context of the culture and value systems in which they live and in relation to their goals, expectations, standards and concerns. QoL - defined as the presence of a physical, mental and social well-being that allows a fulfilling personal life, not merely the absence of disease - has become a significant parameter in healthcare practice and research[15].

Measurement of QoL is a subjective self-evaluation of the multidimensional impact of clinical status and therapy in patients' daily life [16, 17]; it does not reflect objectively the clinical or psychological status [13], but provides very valuable data that cannot be obtained using clinical, biological or imagistic measurement [5]. Therefore, the various questionnaires that allow measurement of QoL in patients with HF have become extremely valuable instruments. The most widely used in clinical trials and the one who has shown the best psychometrical qualities is the Minnesota Living with Heart Failure Questionnaire (MLHFQ)[18, 19]. Using the global score and various scores that reflect the impact on physical, emotional and social status, the MLHFQ allows to measure the current status and to monitor the evolution of QoL[20].

It is extremely necessary to adequately measure the QoL because a decrease in OoL is associated with frequent rehospitalizations and (increases) cost of healthcare, while the severity of its impairmend is a strong predictor of mortality and morbidity after hospital discharge[21]. Therefore, maintaing a good QoL is as important as survival for patients with 
progressive chronic diseases[22], including those with HF.

Moreover, patients with symptomatic HF perceive a QoL impairment similar to those undergoing dialysis but greater than those with chronic pulmonar diseases or chronic arthritis[13, 15]. The level of QoL impairment increases with the level of $\mathrm{HF}$ and correlates with NYHA class and 6-minute walking test but not with ejection fraction[13]. The increase in NYHA class increases the global impairment of QoL that is additional to decreased physical and emotional status[13].

QoL is influenced not only by the severity of symptoms (left ventricular dysfunction, NYHA class etc.) but also by individual parameters (demographical - sex, age etc., psychological coping with stress, anxiety, depression, mental status, motivation, personality, behavioral parameters etc.)[20] and environmental parameters (such as social, emotional and social support)[23-25].

Severity of symptoms is responsible for $20 \%$ of the decrease in QoL, while psychological factors such as vitality and mental health account for 34\%[13]. Female sex, young age, rural background, low socioeconomic status, lesser education, lack of partner, anxiety and depression are associated with a higher decrease in QoL[23]. [QoL is evaluated differently by the patiens with HF, their doctors and patients with other chronic conditions [26, 27] .

Several studies/trials have shown that participating in a cardiac rehabilitation (CR) program is influenced by several individual and context-related factors such as male sex, age under 65 years, perceptions about the program and owning a vehicle. Women tend to report more physical limitations and depressive symptoms than men[20], therefore they are more predisposed to quit CR programs [28]. They have personal/intrapersonal reasons (self-reported mental health, health beliefs), interpersonal reasons (family caregiver role, work conflicts/conflicts at work), logistical reasons (transportation, distance), CR program-related reasons (perception of the objective of CR, exercise component, inconvenient timing, CR equipment) and healthcare reasons (financial support for transportation, long waiting list); some of these reasons could also be characteristic to men as well. Therefore, psychological evaluation and counseling should represent essential components of CR, especially for patients with depressive symptoms, because they quit CR more frequently, in addition to a flexible and modular schedule and improvement in financial support (for transportation etc.)[29].

Because patients with an active involvement in care feel they can control disease symptoms and evolution and therefore have a higher physical status and higher QoL[25], there have been designed and implemented programs for self-management. Within these programs, patiens receive support related to symptom monitoring, enhancing problem-solvin and decisionmaking skills for medical treatment management and healthy lifestyle). A meta-analysis by Jonkman and colleagues has shown the efficiency of these programs depends on their duration rather on their content. These programs should include family members as well and provide tailored solutions that are accessible and beneficial to patients with low socioeconomic and educational level[30, 31].

Beside exercise training, nutritional counseling, psychosocial support and intervention these programs should include strategies to optimize and increase adherence to lifestyle changes and medical treatment in order to achieve sustained benefits for patients in CR programs, improving their physical and psychoemotional well-being and terefore increasing their QoL.

Clinicians should understant the whole range of issues affecting QoL in patients with HF because the patients' uncertainty regarding the disease outcome is as significant as psychosocial aspects.

In conclusion, living with chronic heart disease requires an important cognitive and behavioral effort and significantly affects QoL in all patients, subject to cultural and social factors affecting them. Accurate measurement of QoL is extremely important because it provides significant data for the rehabilitation. Adequate knowledge of resources and demands of heart failure patients is relevant to the cardiac rehabilitation process, to the emotional and wellbeing and also has practical consequences in guiding the therapy. Addressing these, often neglected, aspects of care can be important to the rehabilitation process and the emotional and mental well-being of these patients.

\section{Bibliography}

1. Farcaş AD NL. Factors Influencing the Perception of Stress in Patients with Heart Failure Procedia-Social and Behavioral Sciences. 2014;127:144-8.

2. Caughey MC, Sueta CA, Stearns SC, Shah AM, Rosamond WD, Chang PP. Recurrent Acute Decompensated Heart Failure Admissions for Patients With Reduced Versus 
Preserved Ejection Fraction (from the Atherosclerosis Risk in Communities Study). The American journal of cardiology. 2018;122(1):108-14.

3. Cleland JG, Swedberg K, Follath F, Komajda M, CohenSolal A, Aguilar JC, et al. The EuroHeart Failure survey programme-- a survey on the quality of care among patients with heart failure in Europe. Part 1: patient characteristics and diagnosis. European heart journal. 2003;24(5):442-63.

4. Wang TJ, Wollert KC, Larson MG, Coglianese E, McCabe EL, Cheng S, et al. Prognostic utility of novel biomarkers of cardiovascular stress: the Framingham Heart Study. Circulation. 2012;126(13):1596-604.

5. Farcas AD, Stoia MA, Anton FP, Hognogi DM, Ianos RD, Hojda SES, et al. The Lymphocyte Count and Neutrophil/lymphocyte Ratio are Independent Predictors for Adverse Cardiac Events in Ischemic Heart Failure but not with Non-ischemic Heart Failure. Rev Chim. 2016;67(10):2091-4.

6. Goidescu CM, Farcas AD, Anton FP, Simiti LAV. The Pattern of Ventricular Remodeling Influences the Level of Oxidative Stress in Heart Failure Patients. Rev Chim. 2017;68(7):1506-11.

7. De la Cámara AG GJ, Tapia PM, Esteban EA, Vázquez Fernández del Pozo S, Sandubete EC, Medrano Ortega FJ, Puerto AN, Marín-León I on the behalf of PREDICE Group. Role of biological and non biological factors in congestive heart failure mortality: PREDICE-SCORE: A clinical prediction rule. Cardiology Journal. 2012;19(6):578-85.

8. Alexescu TG, Cozma A, Sitar-Taut A, Negrean V, Handru MI, Motocu M, et al. Cardiac Changes in Overweight and Obese Patients. Rom J Intern Med. 2016;54(3):161-72.

9. Fodor A, Cozma A, Karnieli E. TBC update: personalized epigenetic management of diabetes. Pers Med. 2017;14(6):531-49.

10. Fringu F. CB, Gurzau D., Comsa H., Gușetu G., Zdrenghea D., Pop D. Cardiac rehabilitation in patients with heart failure and diabetes mellitus. Balneo Research Journal. 2018;9(2):73-5.

11. Gasiorowski A, Dutkiewicz J. Comprehensive rehabilitation in chronic heart failure. Annals of agricultural and environmental medicine : AAEM. 2013;20(3):606-12.

12. Pop D CB, Cismaru G, Guşetu G, Roşu R, Comşa H, Zdrenghea DT. Secondary prevention- an essential component of the comprehensive rehabilitation of patients with heart failure. Balneo Research Journal. 2017;8(4):2179.

13. Juenger J SD, Kraemer S, Haunstetter A, Zugck C, Herzog W, Haass M. . Health related quality of life in patients with congestive heart failure: comparison with other chronic diseases and relation to functional variables. Heart. 2002;87:235-41.

14. http://www.who.int/mental_health/media/68.pdf

15. Coelho R, Ramos S, Prata J, Bettencourt P, Ferreira A, Cerqueira-Gomes $\mathrm{M}$. Heart failure and health related quality of life. Clinical Practice and Epidemiology in Mental Health. 2005;1(1):19.

16. Majani G PA, Giardini A, Callegari S, Opasich C, Cobelli F, Tavazzi L. . Relationship between psychological profile and cardiological variables in chronic heart failure. The role of patient subjectivity. European heart journal cardiovascular Imaging. 1999;20(21):1579-86.

17. Sneed NV PS, Michel Y, Vanbakel A, Hendrix G. . Evaluation of 3 quality of life measurement tools in patients with chronic heart failure. . Heart Lung 2001;30(5):332-40.

18. Garin O HM, Vilagut G, et al. . Assessing health-related quality of life in patients with heart failure: a systematic, standardized comparison of available measures. . Heart Fail Rev. 2014;19(3):359-67.

19. Zambroski CH MD, Bhat G, Ziegler C. . Impact of symptom prevalence and symptom burden on quality of life in patients with heart failure. Eur J Cardiovasc Nurs. 2005;4(3):198-206

20. Pelegrino VM SDR, Clark MA. Health-related quality of life determinants in outpatients with heart failure. Revista Latino-Americana de Enfermagem. 2011;19:451-7.

21. Alla F BS, Guillemin F, Juilliere Y, Mertes PM, Villemot JP, Zannad F. PubMed: 12034160. Self-rating of quality of life provides additional prognostic information in heart failure. Insights into the EPICAL study. . Eur $\mathrm{J}$ Heart Fail 2002;4(3):337-343(3):337-43.

22. Lewis EF JP, Johnson W, Collins C, Griffin L, Stevenson LW. . Preferences for quality of life or survival expressed by patients with heart failure. . J Heart Lung Transplant 2001;20(9):1016-24.

23. Farcaş AD NL. Quality of life in patients with chronic congestive heart failure. . HVM Bioflux. 2011;3(3):239-45.

24. Johansson P DU, Broström A. Factors and interventions influencing health-related quality of life in patients with heart failure: a review of the literature. E. Eur J Cardiovasc Nurs. 2006;5(1):5-15.

25. Carels RA. The association between disease severity, functional status, depression and daily quality of life in congestive heart failure patients. Qual Life Res. 2004;13:6372.

26. Grigioni F CS, Grandi S, Potena L, Coccolo F, BacchiReggiani L, Magnani G, Tossani E, Musuraca AC, Magelli C, Branzi A. . Distance between patients' subjective perceptions and objectively evaluated disease severity in chronic heart failure. . Psychother Psychosom. 2003;72(3):166-70.

27. Heo S LT, Okoli C, Moser DK. . Quality of life in patients with heart failure: ask the patients. . Heart Lung 2009;38(2):100-8.

28. Ruano-Ravina A P-GC, Abu-Assi E, Raposeiras S, van't Hof A, Meindersma E, et al. Participation and adherence to cardiac rehabilitation programs. A systematic review. Int J Cardiol. 2016;223:436 - 43

29. Resurreccion DM ME, Rubio- Valera M, Mora-Pardo JA, Moreno-Peral P. Reasons for dropout from cardiac rehabilitation programs in women: A qualitative study. PLoS ONE 2018;13(7):e0200636

30. Jonkman NH WH GR, Ågren S, Anguita M et al. . What Are Effective Program Characteristics of Self-Management Interventions in PatientsWith Heart Failure? An Individual Patient Data Meta-analysis. . Journal of cardiac failure 2016;22(11):861-71

31. Rabelo ER AG, Domingues FB, Ruschel KB, Brun AO. What to teach to patients with heart failure and why: the role of nurses in heart failure clinics. . Rev Latino-Am Enfermagem 2007;15(1):165-70. 